\title{
Design of PI Controller using Characteristic Ratio Assignment Method for Coupled Tank SISO Process
}

\author{
M.Senthilkumar \\ Dr.S.AbrahamLincon \\ Assistant Professor \\ Professor \\ Department of Instrumentation Engineering \\ Annamalai University, Annamalai Nagar, India
}

\author{
P.Selvakumar \\ M.E., Student
}

\begin{abstract}
This paper presents the PI controller design for coupled tank as Single Input Single Output (SISO) process using Characteristic Ratio Assignment (CRA) method.CRA is an approach to directly control the transient response of linear time invariant control systems. The transient response for all pole transfer function of $\mathrm{n}^{\text {th }}$ order system can be controlled by introducing a set of parameters $\left(\alpha_{\mathrm{i}}\right)$ characteristic ratio, $(\mathrm{i}=1,2, \ldots, \mathrm{n})$ and $(\tau)$ generalized time constant.The CRA method which satisfies more specification and performance of control system. The coupled tank as SISO process is a challenge plant for testing the performance of PI controller. The fundamental model of coupled tank as SISO process is obtained and CRA based PI controller is designed. Using a CRA-PI controller the simulation results has been simulated by MATLAB and real time results also can be implemented for coupled tank as SISO process.
\end{abstract}

\section{Keywords}

Characteristic Ratio Assignment (CRA), SISO process, PI Controller.

\section{INTRODUCTION}

Most control performances in actual design are usually defined by the time domain responses such as overshoots, rising time, settling time, steady state error, etc. There are few control design methods, which are able to apply directly to the purpose. The pole placement method is the most popular in control systems. This CRAis one technique of pole placement based on defined parameter of characteristic equation. These techniques can adjustment of speed of response and the damping ratios.

The CRA method is one technique based on defined parameter of characteristic equation that is a famous method at present [1]. In controller design [2], by CRA method, the adjustment of speed of response and the damping ratio can be achieved by the parameters time constant $(\tau)$ and characteristic ratio $\left(\alpha_{i}\right)$. Therefore, this technique is convenient and suitable for tuning controller under the requirement of the system. The main ideas are based on certain relations between the characteristic polynomial coefficients and time domain responses.

This paper gives the coupled tank as SISO process of CRA-PI controller based on CRA method.

\section{DESIGN OF COUPLED TANK SISO PROCESS}

The schematic diagram of coupled tank as SISO process as shown in Figure1. The inflow of tank1 is $F_{\text {in }}$ and outflow of tank2 is $F_{\text {out }}$. The control variable is level in tank2.

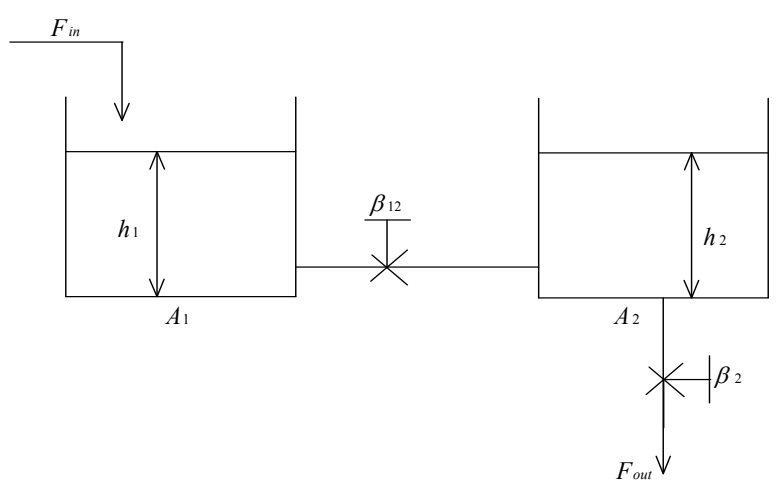

Fig 1: Thecoupled tank SISOprocess

The nonlinear equation from Bernoulli's law

$$
\begin{aligned}
& \frac{d h_{1}(t)}{d t}=-\frac{\beta_{12} a_{12}}{A_{1}} \sqrt{2 g\left(h_{1}(t)-\left(h_{2}(t)\right)\right.}+\frac{k}{A_{1}} u(t)(1) \\
& \frac{d h_{2}(t)}{d t}=-\frac{\beta_{2} a_{2}}{A_{2}} \sqrt{2 g\left(h_{2}(t)\right)}+\frac{\beta_{12} a_{12}}{A_{2}} \sqrt{2 g\left(h_{1}(t)-\left(h_{2}(t)\right)\right.}
\end{aligned}
$$

Where

$$
\begin{array}{ll}
\mathrm{A}_{1}, \mathrm{~A}_{2} & \text { - Cross sectional area of tank1 and tank2 } \\
\mathrm{a}_{2} & \begin{array}{l}
\text { - Cross sectional area of output pipe in } \\
\text { tank2 }
\end{array} \\
\mathrm{a}_{12} & \begin{array}{l}
\text { - Cross sectional areaof interaction pipe } \\
\text { betweentank1 and tank2 }
\end{array} \\
\mathrm{h}_{1}, \mathrm{~h}_{2} & \text { - Water level of tank1 and tank2 } \\
\mathrm{F}_{\text {in }} & \text { - Inflow (lph) } \\
\mathrm{F}_{\text {out }} & \text { - Outflow (lph) } \\
\beta_{12} & \text { - Valve ratio of jointed pipe between tank1 } \\
& \text { and tank2 } \\
\beta_{2} & \text { - Valve ratio at the outlet of tank2 } \\
\mathrm{k} & \text { - Gain of the pump } \\
\mathrm{g} & \text { - Gravity } \\
\mathrm{u} & \text { - Input voltage }
\end{array}
$$


The equations (1) and (2) can be linearisedandpresented as

$$
\begin{aligned}
& \frac{d H_{1}(t)}{d t}=\frac{1}{T_{12}}\left(-H_{1}(t)+\left(H_{2}(t)\right)+\frac{k}{A_{1}} U(t)\right. \\
& \frac{d H_{2}(t)}{d t}=\frac{1}{T_{2}}\left(-H_{2}(t)+\frac{1}{T_{12}}\left(H_{1}(t)-H_{2}(t)\right)\right.
\end{aligned}
$$

Where

$T_{12}=\frac{A_{1}}{\beta_{12} a_{1}} \sqrt{\frac{2\left(h_{1}-h_{2}\right)}{g}}, s$

$T_{2}=\frac{A_{2}}{\beta_{2} a_{2}} \sqrt{\frac{2\left(h_{2}\right)}{g}}, s$

$\mathrm{T}_{12}$ - Time constant between tank1 and tank2

$\mathrm{T}_{2}$ - Time constant of tank2

The transfer function of a coupled tank as SISO process is obtained from the linear equations(3) and (4) as

$\frac{H_{2}(s)}{U(s)}=G(s)=\frac{K}{T_{12} T_{2} s^{2}+\left(T_{12}+2 T_{2}\right) s+1}$

Where

$$
K=\frac{k T_{2}}{A_{2}}, \mathrm{~cm} / V
$$

\section{CRA CONTROL SYSTEM}

The control system structure is two degree of freedom that its parameters are determined by CRA method. The block diagram for CRA control system as shown in Figure 2.

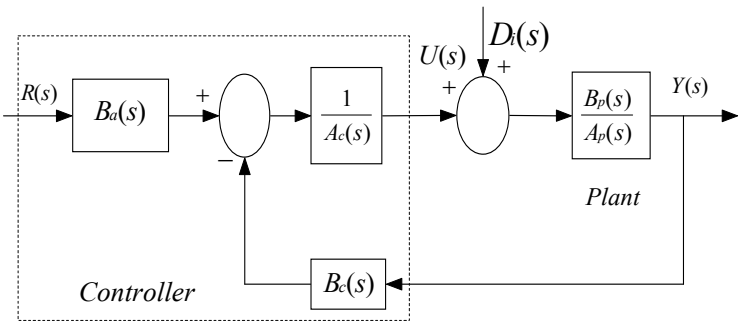

Fig2:Block diagram of CRA control system

The general function as

$$
\frac{Y(s)}{R(s)}=\frac{B_{a}(s) B_{p}(s)}{A_{c}(s) A_{p}(s)+B_{c}(s) B_{p}(s)}
$$

Where

$\mathrm{B}_{\mathrm{p}}(\mathrm{s})$ and $\mathrm{A}_{\mathrm{p}}(\mathrm{s})$ are the polynomial equations.

For this case the functions are as
$B_{p}(s)=K ; A_{p}(s)=T_{12} S^{2}+\left(T_{12}+2 T_{2}\right) s+1$

$A_{c}(s)=s, B_{c}(s)=K_{p} s+K_{i}, B_{a}(s)=K_{i}(8)$

The polynomial characteristic equation as

$p(s)=T_{12} T_{2} s^{3}+\left(T_{12}+2 T_{2}\right) s^{2}+\left(1+K K_{p}\right) s+K K_{i}(9)$

Equation (9) is the polynomial characteristic equation to design the PI controller using by CRA method.

\section{DESIGN OF CRA METHOD}

The relation of characteristic equation can be illustrated as

$p(s)=a_{n} s^{n}+a_{n-2} s^{n-2}+a_{n-1} s^{n-1} \ldots . .+a_{1} s+a_{0}(10)$

Where

$a_{i}>0$

The characteristic ratio is given by

$\alpha_{1}=\frac{a_{1}^{2}}{a_{0} a_{2}}, \alpha_{2}=\frac{a_{2}^{2}}{a_{1} a_{3}},, \cdots, \frac{-1^{2}}{-2 a_{n}}(11)$

The inverse of characteristic equation is given as

$b_{0}=\frac{a_{0}}{a_{1}}, b_{1}=\frac{a_{1}}{a_{2}} b_{r} \quad, \ldots .$.

The relation of coefficient ratio and characteristic pulsatances as

$$
\alpha_{1}=\quad, \ldots, \quad \frac{b_{2}}{b_{1}} \alpha_{n-1}=\frac{b_{n-1}}{b_{n-2}}
$$

The time constant is given by

$\tau=\frac{a_{1}}{a_{0}}$

From equation (11) and (13) to describe in another form by the coefficient of the characteristic equation as

$A=\left[\begin{array}{llll}a_{n} & a_{n-1} & \ldots & a_{1} a_{0}\end{array}\right]$

$B=\left[\begin{array}{llll}b_{n-1} & b_{n-2} & \ldots & b_{1} b_{0}\end{array}\right](16)$

$\mathrm{C}=\left[\begin{array}{llll}c_{n-2} & c_{n-3} & \ldots & c_{1} c_{0}\end{array}\right](17)$

Where

$b_{i}=\frac{a_{i}}{a_{i+1}}, i=0,1,2, \ldots ., n-1$

$c_{i}=\frac{b_{i+1}}{b_{i}}, i=0,1,2, \ldots ., n-2$ 
Design of controller by CRA method, assigns value of time constant ( ) and characteristic ratio $\left(\alpha_{\mathrm{i}}\right)$ to system requirement.

For the coupled tank as SISO process the parameters are tabulated as below.

Table I.Parameters of Coupled Tank SISO Process

\begin{tabular}{|c|c|c|c|}
\hline $\mathbf{A}_{\mathbf{1}}, \mathbf{A}_{\mathbf{2}}$ & $\mathbf{a}_{\mathbf{2}}, \mathbf{a}_{\mathbf{1 2}}$ & $\boldsymbol{\beta}_{\mathbf{2}}$ & $\boldsymbol{\beta}_{\mathbf{1 2}}$ \\
\hline 154 & 0.5 & 0.6820043 & $\begin{array}{c}1.531519 \\
5\end{array}$ \\
\hline
\end{tabular}

Table II. Operating Point of Coupled Tank SISO Process

\begin{tabular}{|c|c|c|c|}
\hline $\mathbf{h}_{\mathbf{1}}$ & $\mathbf{h}_{\mathbf{2}}$ & $\mathbf{u}$ & $\mathbf{k}$ \\
\hline 29.55 & 24.66 & 2.5 & 30.0024 \\
\hline
\end{tabular}

\section{THE SIMULATION RESULTS}

The simulation results of coupled tank as SISO process is simulated using by MATLAB. The simulation results of PI controller based on CRA method is illustrated. Using the Table1 parameters and Table2 operating points the transfer function for coupled tank SISO process as

$$
G(s)=\frac{19.7277}{2033.30981 s^{2}+222.60117 s+1}
$$

According to equations(1) and (2), the design of PI controller based on CRA is assigned

Theassigned parameters are as

$$
a_{0}=1 ; \alpha_{1}=1.8 ; \alpha_{2}=2 \text { and } \tau=40
$$

The target polynomial is obtained for SISO process as

$$
p(s)=9876.54321 s^{3}+888.8888 s^{2}+40 s+1(21)
$$

Using the equation (20) and (21) the parameters of PI controller is given by

$$
K_{p}=1.9769 ; K_{i}=0.03069
$$

For the SISO process a design of CRA-PI controller theperformance levels are illustrated by simulation.

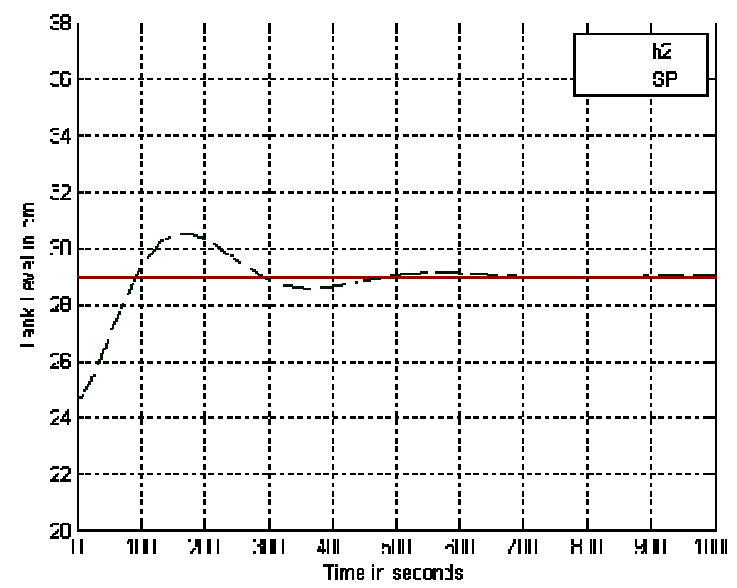

Fig 3: Closed loop responses of CRA-PI controller for coupled tank SISO process

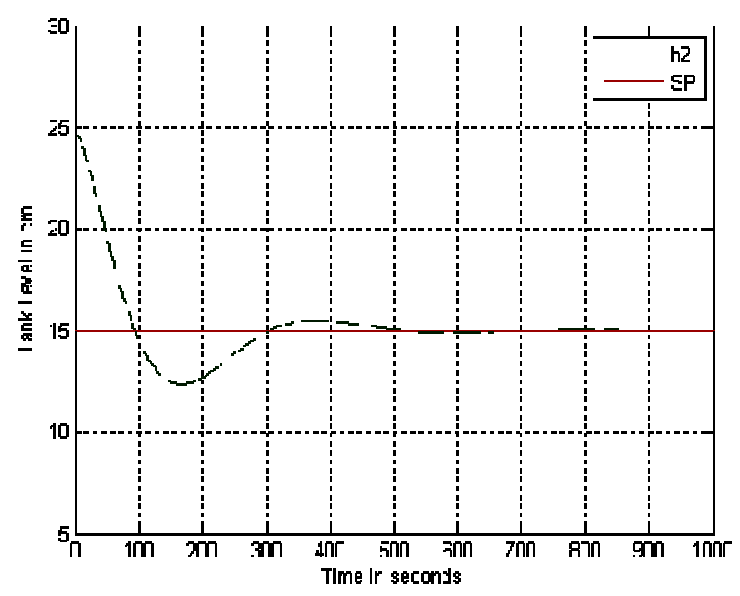

Fig 4: Closed loop responses of CRA-PI controller for coupled tank SISO process

\section{EXPERIMENTAL STEUP}

In this section, the coupled tank as SISO process the nonlinear and linear equations has been modified using CRA-PI Controller. The experimental model of SISO process is shown in Figure 5.

\subsection{Description of the System}

The schematic diagram of coupled tank as SISO process is shown in Figure 5. The process is composed two identical tanks with cross sectional area of A. The inlet flow of tank 1 is $F_{\text {in }}$ and the outlet flow of tank2 is $F_{\text {out }}$. A manual valve is available between tank1 and tank 2 can be adjusted to change the interaction between the tanks. Tank1 permits the water supply and tank 2 is the outlet flow of the system. The water level variation of tank1 and tank2 depends on the input and output flows. The control of input voltage is $\mathrm{u}$. The control variable is level in tank2. The level is measured using differential pressure transmitter and fed to the personal computer through the VDPID-03 interfacing card. 


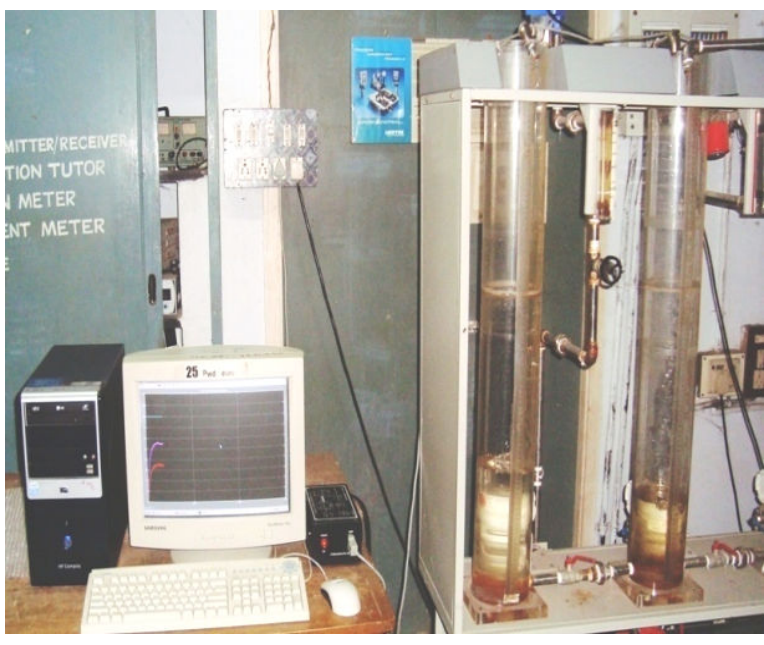

$K_{p}=1.9769 ; K_{i}=0.03069$

Fig 5:Photograph of coupled tank SISO process

The physical parameters of the two tank system are shown inthe Table III.

Table III. PhysicalParameters of Coupled Tank System

\begin{tabular}{|l|l|}
\hline \multicolumn{1}{|c|}{ Parameters } & \multicolumn{1}{c|}{ Values } \\
\hline Tank Cross Section Area & $\mathrm{A}=154 \mathrm{~cm}^{2}$ \\
\hline Pipe area cross section & $\mathrm{a}=0.5 \mathrm{~cm}^{2}$ \\
\hline Tank Water levels & $\mathrm{h}_{1}=29.55 \mathrm{~cm}, \mathrm{~h}_{2}=24.66 \mathrm{~cm}$ \\
\hline Tank valve ratios & $\beta_{2}=0.6820043, \beta_{12}=1.5315195$ \\
\hline Input voltage & $\mathrm{u}=2.5 \mathrm{~V}$ \\
\hline Gravity & $\mathrm{g}=981 \mathrm{~cm}^{2} / \mathrm{s}$ \\
\hline Pump gain & $\mathrm{k}=30.0024 \mathrm{~cm}^{3} / \mathrm{V} . \mathrm{s}$ \\
\hline
\end{tabular}

\section{EXPERIMENTAL RESULTS}

To substitute Table III parameters in equations (20) and (21) to designof PI Controller is given by
For the SISO process a design of CRA-PI controller at various performance levels are illustrated by experimental setup.

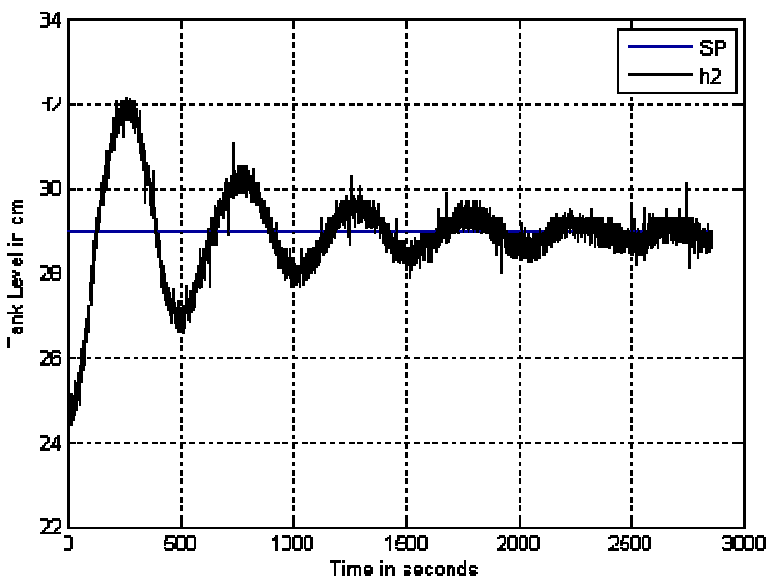

Fig 6: Real time closed loop response of CRA-PI controller for coupled tank SISO process

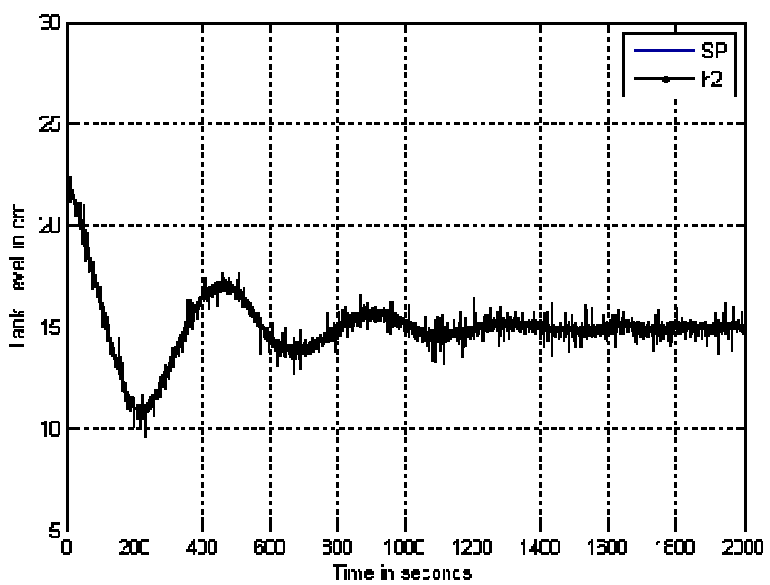

Fig 7: Real time closed loop response of CRA-PI controller for coupled tank SISO process

\section{CONCLUSIONS}

The design procedures of the PI controller by CRA method for SISO process have been proposed in this paper. The closed loop response of a SISO system and controller output of a SISO system has been compared in both simulation and real time using CRA-PI Controller. From the simulation using MATLAB and real time results illustrated that the CRA based controller have been designed conveniently with the advantage of choosing only one parameter of characteristic ratio $\left(\alpha_{i}\right)$. 


\section{REFERENCES}

[1] Jayasuriya, S and Song,J.W. "On the synthesis of Compensators for non overshooting step response" Proc.1992, Amer Control Conf., pp.683-684, 1992.

[2] Kim,Y.C.. Keel,L.H. and Bhattacharya,S.P., "Transient Response Control via Characteristic Ratio Assignment" IEEE Transactions on Automatic Control Dec.2003, Vol.48, No.12:pp.2238-2244.

[3] Naslin,P. Essentials of Optimal Control, London Boston Technical Publishers, Inc., Cambridge, MA,1969.

[4] Quing-Guo Wang, Tong-hengLee,Ho-Wang Fung,QiangBi,Yuzhang, "PID Tuning for Improved Performance", IEEE Transactions on Control System Technology, Vol.7, No.4, July $1999 .$.

[5] Bernardo A. Leon de la Barra Francisco.J.Salazar, "On Undershoot in SISO", IEEE Transaction on Automatic Control, Vol. 39, No.3, Mar, 1994.

[6] Battacharyya,S.P.,Chapellat,H. and Keel,L.H., Robust Control: The Approach, Prentice Hall PTR, Upper Saddle River, NJ, 1995.

[7] Majhi,S, "SISO Controller for TITO systems", presented at the Int., Conf., on Energy, Automation and Information Tech., 2001.
[8] Zhuang,M. and Athetron,D.P. "PID Controller Design for a TITO System", IEEE Proc - Control Theory Appl., Vol.141, No.2, pp.111-120, 1994.

[9] Numsomran,A.Wongkhum,T.Suskri ,T. Nilas, P.Chaoraingern, J.,'Design of decoupled controller forTITO system using characteristic ratio assignment", ICCAS'07 . International Conference on Control, Automation and systems, 2007, pp 957-962.

[10] YoungcholKim, .Keunsik Kim, ShunjiManabe.,"Sensitivity of Time Response to Characteristic Ratio",IEICE Trans, Fundamentals, Vol.E89-A ,2006

[11] Kim,Y.C., Keel,L.H and Bhattacharyya,S.P., "Transient response control via characteristic ratio assignment", Technical Report, No. ISE-01-09-1, Center of Excellence in Information Systems, Tennessee State University, September 2001

[12] Naslin,P.The Dynamics of Linear and Non Linear Systems, Cordon and Breach Science Publishing, New York, NY, 1965.

[13] Chaoraingern J., Trisuwannawat T., Numsomran A.,"PID Controller Design for Following Control of Hard Disk Drive by characteristic ratio Assignment method ".,WASET ,pp 7379,2009 .

[14] [ Manabe, S., "Coefficient Diagram Method ", Proceedings of $14^{\text {th }}$ IFAC Symposium on Automatic Control in Aerospace, Seoul, 1998 